\title{
On the Integrated Usage of Atomic and Nuclear Approaches for Detecting Potentially Hazardous Elements*
}

\author{
Ashraf S. Elkady ${ }^{1,2}$, Walaa M. Abdel-Aziz ${ }^{2}$ \& Ibrahim I. Bashter ${ }^{3}$ \\ ${ }^{1}$ Department of Physics, Faculty of Science for Girls, King Abdulaziz University, Jeddah, KSA \\ ${ }^{2}$ Department Reactor Physics, NRC, Egyptian Atomic Energy Authority (EAEA), Cairo, Egypt \\ ${ }^{3}$ Department of Physics, Faculty of Science, Zagazig University, Zagazig, Egypt \\ Correspondence: Ashraf S. Elkady, Physics Department, Faculty of Sciences, King Abdulaziz University, KSA. \\ Tel: 966-543-547-574. E-mail: elkady8@gmail.com \\ * Dedicated as a memorial to Professor Abdel-Monem Hassan, EAEA, Egypt, who passed away on the $2^{\text {nd }}$ of \\ January 2011
}

Received: January 4, $2013 \quad$ Accepted: February 16, $2013 \quad$ Online Published: November 22, 2013
doi:10.5539/eer.v3n2p224
URL: http://dx.doi.org/10.5539/eer.v3n2p224

\begin{abstract}
In this work, we report on the usage of different atomic and nuclear approaches for detecting hazardous elements in some commercially available eye cosmetics. Recent studies showed that some eye cosmetics (e.g. eye-liners like kohl) might have hazardous and toxic elements in its elemental composition, which would harmfully impact on the environment and health of its users. In order to obtain accurate information on the elemental content of some natural and synthetic eye-liners that are commercially available in the Egyptian markets and pharmacies, we have applied Energy Dispersive X-ray (EDX), Atomic Absorption Mass Spectroscopy (AA-MS), Elemental Analyzer (EA), and Neutron Activation Analysis (NAA). Heavy and toxic elements, as well as short and long lived radionuclides concentration values were identified in the studied samples. The results indicate that among the three studied samples, the highest lead containing sample is the natural unprocessed one of African source; while the most abundant element in the synthetic samples made in France and USA is Carbon. The present study raises a concern about the medical and environmental implications of using eye-liners, and emphasizes the vital role played by atomic and nuclear approaches in detecting hazardous elements in such commercially available products.
\end{abstract}

Keywords: atomic and nuclear approaches, hazardous elements, eye cosmetics, energy dispersive x-ray spectroscopy, neutron activation analysis

\section{Introduction}

Traditional medicine plays an important role and has a direct impact on the general state of population health (Lekounch et al., 2001). However, many medical remedies and mixtures used in this medicine can present a health risk due to the presence of toxic products such as trace elements of lead, cadmium, mercury...etc (Al-Saleh \& Coat, 1995). The usage of traditional cosmetics and remedies such as kohl, henna, teething powder... etc, are very common, especially among women, children and babies (Khassouni, 1993).

Kohl is traditional eyeliner that has been widely used as an eye cosmetic in the Middle East, Far East, and Northern Africa (Al-Hawi, 1980). It is both used for beautification and as a traditional ethnic remedy to relieve eyestrain, pain, or soreness. In addition, kohl is known to prevent sun glare, thus it was used by Bedouins in the Arab peninsula. Previous studies (Al-Hazzaa, 1995; Hardy et al., 2004) have shown that kohl contains toxic heavy metals, such as lead, and case studies have revealed that blood lead levels were significantly higher in individuals who used kohl compared to ones who did not (Al-Ashban et al., 2004).

The extensive use of green, white and black make-up has been known since the earliest periods of Egyptian history (Walter et al., 1999). Recently, some authors have suggested the potential adverse effects of some eye make-ups on health, such as lead poisoning that makes them a health risk and of worth investigation in different countries (Carol \& Joseph, 1991; Hardy et al., 2004; Karim et al., 2005). Besides, a diverse array of nanomaterials including nanocosmetics, has become widespread in use due to the fast development of nanotechnology applications. However, the safety of such materials has not been well assessed, because they 
have been considered as safe as common larger sized materials, which are known not to be absorbed by the body (Yoshida et al., 2012). Indeed, this is not true due to the fact that when the cosmetic particles size is reduced down to nanoscale, they become more able to penetrate cellular and brain barrier membranes. Thus, the wide use of very fine particles of kohl on the eyes of children and adults motivated us to investigate whether kohl is a possible source of exposure to lead and other toxic elements in Egypt.

In this context, there are different atomic and nuclear techniques that can be used for elemental analysis and for detecting toxic and hazardous heavy elements. However, each technique has its detection limit, accuracy and sensitivity to certain elements. Neutron activation analysis (NAA) is considered one of the most important analytical nuclear approaches, which yield a precise result for trace and ultra-trace elemental concentrations in complex samples. Along the past several decades, it was successfully applied for determination of a great variety of elements in many disciplines including environmental (Landsberger, 1992), biological (Erdtmann \& Petri, 1986), geological as well as material sciences (Martinez, 1997). It is considered as a method for qualitative and quantitative determination of elements based on the measurement of characteristic radiation from radionuclides formed directly, or indirectly by neutron irradiation of samples (Hassan et al., 1994). The most suitable source for neutrons to be used in this technique is usually a nuclear research reactor. The high resolution gamma-ray detection systems are used for analysis of the complex gamma-ray spectra obtained by neutron capture.

In the present study, we applied different atomic and nuclear approaches, namely Energy Dispersive X-ray (EDX), Atomic Absorption Mass Spectroscopy (AA-MS), Elemental Analyzer (EA) and Neutron Activation Analysis (NAA) in order to obtain more information on the composition and elemental content of some natural and synthetic eye-liner samples taken from the Egyptian markets and pharmacies. The emphasis will be on the medicinal implications of using eye-liners with high content of lead and toxic elements, and on the vital role that atomic and nuclear methods play in detecting such hazardous elements in eye-cosmetics.

\section{Materials and Methods}

\subsection{Samples Preparation}

Samples of kohl used in this work were purchased from local Egyptian markets and pharmacies in Cairo. Three commonly used representative samples were chosen for analysis. The African natural untreated eye-liner was in big crystallized stone form, while the American and French synthetic kohl were in pencil forms. The samples were crushed, finely grounded into powder form before investigations.

\subsection{Experimental Approaches}

Different atomic and nuclear approaches were applied in order to obtain a complete picture of the elemental content in the studied samples, and avoid the limitation and accuracy of a single approach.

Atomic Absorption Spectrometer, Energy Dispersive X-ray spectrometer, and Analytical analyzer located in the Central Laboratory of the Nuclear Research Center (NRC), Egypt were used to identify the chemical elements present in the samples under investigation. Briefly, a flame atomic absorption spectrometer was used in order to analyze the samples for their elemental constituents. The samples were atomized and optically irradiated; the radiation then passes through a monochromator in order to separate the element-specific radiation from any other radiation emitted by the radiation source, which is finally measured by a detector.

In EDX facility, primary $\mathrm{x}$-rays are illuminated from the $\mathrm{x}$-ray tube to the specimen, fluorescence $\mathrm{x}$-rays having wavelengths (energies) peculiar to the constituent elements of the specimen are generated from the elements. Qualitative analysis can be made by investigating the wavelengths of the fluorescence x-rays and quantitative analysis by investigating the $\mathrm{x}$-ray dose. The energies are investigated by using the energy separation characteristic of x-ray detector (Willard et al., 1988).

The elemental analyzer detector used in this study is a thermal conductivity detector (TCD) sensitive to any substance with thermal conductivity other than that of the carrier gas. The detector consists of a stainless steel block provided with two pairs of filaments (of tungsten rhenium) having the same electrical resistance. The detector is housed in a thermally insulated metal block (detector oven) and maintained at constant temperature. The two pairs of filaments are electrically connected according to a Wheatstone bridge circuit powered at constant voltage. The first pair of filaments are fed with pure carrier gas (reference channel), where the second pair are fed with the gas flowing from the reactor (analytical channel). When the bridge is powered, the filaments are heated at a temperature (resistance) that is a function of the thermal conductivity of the gas feeding the filaments. The reference channel is exposed only to pure carrier gas, whereas the analytical channel is exposed to the reactor effluents (carrier gas + sample).

When pure carrier gas flows through the reference and the analytical channels, a constant temperature gradient is 
established between the elements and the detector walls and the Wheatstone bridge is balanced where there is no output signal. As a component is eluted, a change in heat transfer occurs, with consequent variation of the filaments temperature. Since electric resistance is a function of temperature, the bridge unbalances and the detector generates a signal proportional to the difference in thermal conductivity between the eluted component and the carrier gas. The output signal is then sent to the data acquisition board.

Neutron Activation Analysis (NAA) technique, available at the ET-RR-2 reactor was applied to the natural eye-liner sample that was prepared in dried powder form. The other two samples were too brittle to be irradiated by high flux of neutrons. Briefly, neutrons as well as charged particles can react with isotopes of various elements and produce radioactive nuclides. The characteristic radiation emitted by these nuclides can be used for qualitative and quantitative determination of various elements. In this way, elements in part per million or percentage can be analyzed. Usually, neutrons are used as projectiles and $\gamma$-rays are emitted. Also the high resolution $\gamma$-ray detection system together with the advanced computer programs can help in complete analysis of the data obtained with high accuracy. Neutron fluxes in the order of $1.3 \times 10^{11}$ and $2.7 \times 10^{11} \mathrm{n} \cdot \mathrm{cm}^{-2} . \mathrm{s}^{-1} \mathrm{were}^{-}$ applied for long and short irradiation times respectively during sample irradiation.

For qualitative and quantitative analysis of the minor elements in sample 3, the well-resolved and pronounced $\gamma$-ray lines in the obtained $\gamma$ spectra have been selected, and the well-known analytical equation was used (Nada et al., 2001):

$$
m=\frac{\lambda C M}{\left[\left(\varepsilon I_{r} \sigma_{t h} f N_{0} \phi_{m}\right) e^{-\lambda t_{W}}\left(1-e^{-\lambda t_{i r r}}\right)\left(1-e^{-\lambda t_{C}}\right)\right]}
$$

where $m$ is the mass of the element; $\phi_{m}$ is the thermal neutron flux; $\lambda$ is the decay constant; $C$ is the activity (net peak area of gamma-ray line); $M$ is the atomic mass; $\varepsilon$ is the efficiency of the detection system at the selected full energy peak, $I_{\gamma}$ is the absolute intensity of the gamma-ray line; $\sigma_{t h}$ is the thermal $(\mathrm{n}, \gamma)$ cross-section; $f$ is the isotopic abundance fraction; $t_{w}$ is the cooling time; $t_{i r}$ is the irradiation time, $t_{c}$ is the counting time; and $N_{0}$ is the Avogadro's number. The main factors used in the calculation were the isotopic abundance of the selected isotopes for each element, half-life, cross-section of the $(n, \gamma)$ reaction and the intensity of the selected $\gamma$-ray line (Lederer \& Shirley, 1997).

\section{Results and Discussions}

\subsection{EDX, AA-MS and EA}

The results obtained from EDX measurements are given in Table 1 and Figure 1. It is noticeable that the most predominant elements are $\mathrm{C}, \mathrm{Cu}, \mathrm{Al}$ and $\mathrm{Si}$ in sample 1; C, O, Si, Fe and $\mathrm{Zn}$ in sample 2, while the concentrations of $\mathrm{Pb}$ and $\mathrm{S}$ in sample 3 are considerably high.

Table 1. Elements concentration (\%) in the three samples of eye-cosmetics as detected by EDX

\begin{tabular}{cccc}
\hline Element & Sample 1 (France) & Sample 2 (USA) & Sample 3 (Africa) \\
\hline $\mathbf{C}$ & $94.29 \pm 4.7145$ & $52.14 \pm 2.607$ & ND \\
$\mathbf{O}$ & $\mathrm{ND}$ & $16.83 \pm 0.8415$ & $\mathrm{ND}$ \\
$\mathbf{A l}$ & $1.04 \pm 0.052$ & $1.16 \pm 0.058$ & $0.84 \pm 0.042$ \\
$\mathbf{S i}$ & $1.14 \pm 0.057$ & $2.74 \pm 0.137$ & $\mathrm{ND}$ \\
$\mathbf{C a}$ & $\mathrm{ND}$ & $0.71 \pm 0.0355$ & $\mathrm{ND}$ \\
$\mathbf{M n}$ & $\mathrm{ND}$ & $0.24 \pm 0.012$ & $\mathrm{ND}$ \\
$\mathbf{S}$ & $0.05 \pm 0.0025$ & $\mathrm{ND}$ & $12.34 \pm 0.617$ \\
$\mathbf{K}$ & $0.48 \pm 0.024$ & $\mathrm{ND}$ & $\mathrm{ND}$ \\
$\mathbf{T i}$ & $0.48 \pm 0.024$ & $\mathrm{ND}$ & $\mathrm{ND}$ \\
$\mathbf{F e}$ & $0.39 \pm 0.0195$ & $24.39 \pm 1.2195$ & $\mathrm{ND}$ \\
$\mathbf{C u}$ & $1.27 \pm 0.0635$ & $0.19 \pm 0.0095$ & $\mathrm{ND}$ \\
$\mathbf{Z n}$ & $0.87 \pm 0.0435$ & $1.59 \pm 0.0795$ & $\mathrm{ND}$ \\
$\mathbf{P b}$ & $\mathrm{ND}$ & $\mathrm{ND}$ & $86.82 \pm 4.341$ \\
\hline
\end{tabular}

* ND: Not detected. 


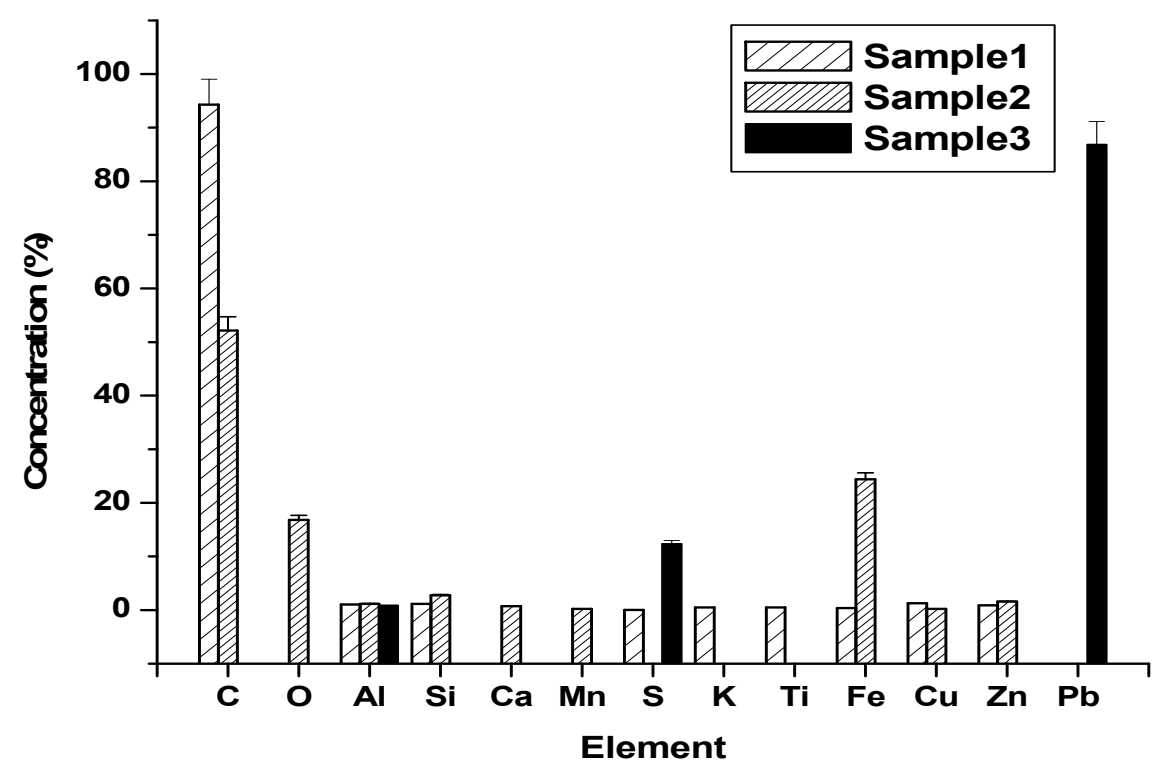

Figure 1. Elements concentration (\%) in the three samples of eye-cosmetics, as detected by EDX

The AA-MS results are represented in Figure 2. One can note that the cupper and iron concentrations are comparable among the three studied samples (see Figure 2). However, the heavy element $\mathrm{Zn}$ is found in considerable concentration in sample 3 and of lower concentrations in sample 1 and sample 2 .

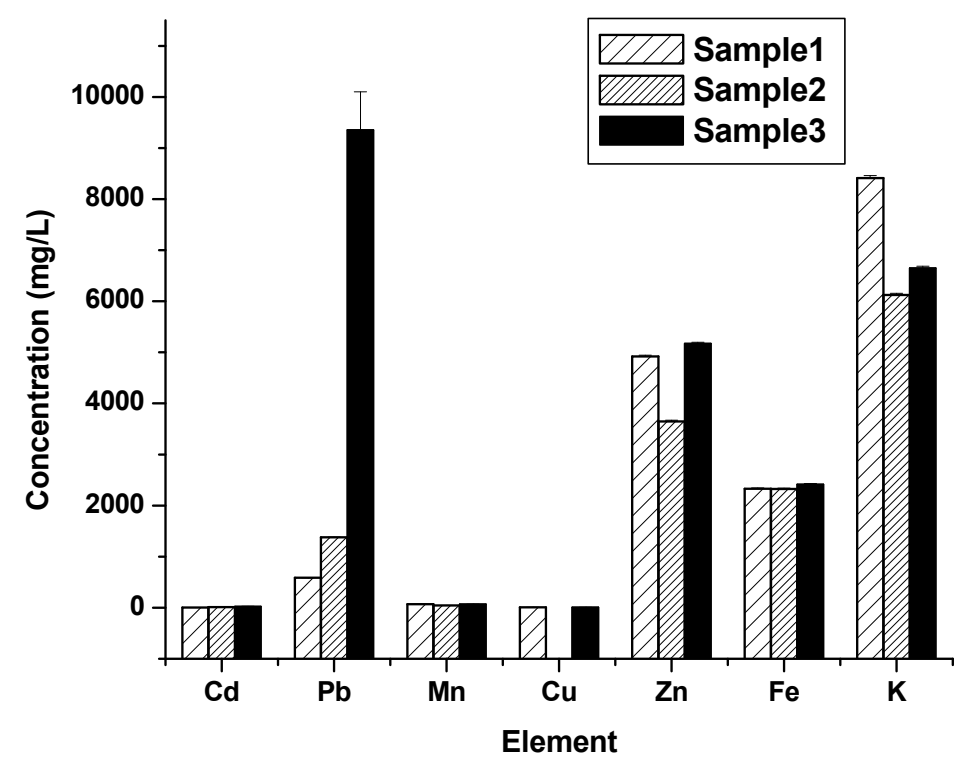

Figure 2. Elements Concentration $(\mathrm{mg} / \mathrm{L})$ in the three samples of eye-cosmetics, as measured by AA-MS. The concentration of $\mathrm{Pb}$ is divided by $10^{2}$

Therefore, out of the three tested set of samples, one contained in excess of $86 \%$ lead (from Africa), the other two samples from France and USA contained about $5 \%$ and $13 \%$ lead respectively. While the concentration of $\mathrm{Al}$ was comparable in the three samples; the $\mathrm{Cd}$ concentration was highest in sample 3 (from Africa) and lowest in sample 1 (from France), as indicated from EDX and AA-MS measurements. There were no significant concentration differences among other elements (e.g. Mn, Si and K) in the three samples according to AA-MS measurements, which are also consistent with EDX measurements.

The elemental analyzer measurements showed that the prevailing element in sample 1 is carbon $(88.34 \%)$, while it is minimal in sample $3(0.25 \%)$. The latter low ratio was not detected by EDX, but was detected by the 
elemental analyzer technique (see Table 2). There is a noticeable agreement in the existing carbon and sulfur concentrations measured using EDX and elemental analyzer facilities.

Table 2. Concentration of $(\mathrm{C}, \mathrm{O}, \mathrm{S})$ in the studied samples $(\%)$, obtained using EA

\begin{tabular}{cccc}
\hline Element & Sample 1 (France) & Sample 2 (USA) & Sample 3 (Africa) \\
\hline C & $88.34 \pm 4.417$ & $52.07 \pm 2.6035$ & $0.2584 \pm 0.01292$ \\
$\mathbf{O}$ & $4.896 \pm 0.2448$ & $8.733 \pm 0.43665$ & $2.2522 \pm 0.11261$ \\
S & ND & ND & $11.23 \pm 0.5615$
\end{tabular}

* ND: Not detected.

From the above described results, it is worth noting that among the detected elements in the composition of samples is lead, which constitutes the main hazardous element. The highest concentration of lead is found in the natural, unprocessed sample from African sources (sample 3), while its concentration was significantly reduced in the other two samples, manufactured in France and USA. Thus, the chemical treatment during manufacture would have its impact on lead content of the processed product.

It is well established that lead is harmful to all adults, children and infants. It is very toxic and can be introduced into the body by ingestion, inhalation, and by skin exposure. Lead poisoning is a global problem, considered to be the most important environmental disease in children (Tong et al., 2000). It is particularly harmful to the developing brain and nervous system. Eye cosmetics like kohl, with high lead concentration, are frequently used by women and as a skin treatment product on infants. High blood lead levels in kohl-using infants and in infants of kohl-using mothers have been reported $(5.2 \mu \mathrm{g} / \mathrm{dl}$ versus $2.8 \mu \mathrm{g} / \mathrm{dl}$ ) and considered abnormal (Nir et al., 1992; Klaasen, 1996; Ahmed et al., 2005). Such abnormal blood lead levels are considered unsafe and have been shown to be associated with intelligence quotient deficits, behavioral disorders, slowed growth, and impaired hearings (Karri et al., 2008; Needleman et al., 2000; Schwartz \& Otto, 1991).

\subsection{Neutron Activation Analysis}

The concentration of minor elements in sample 3 as estimated from $\gamma$-ray spectra, obtained using the short and long irradiation facilities, are given in Tables 3, 4 respectively, and represented in Figure 3 . It is noticeable that among the 8 detected elements by NAA, there are 7 heavy elements, namely Ag, Sb, Mn, Cd, Zn, V and Th. Of worth noting, the $\mathrm{Al}$ and $\mathrm{Cd}$ concentration values obtained from NAA are consistent with their corresponding values obtained using EDX and AA-MS respectively.

Table 3. The heavy elements (except for Al) concentrations in sample 3 as obtained from NAA, using the short irradiation facility

\begin{tabular}{cc}
\hline Element & Concentration $(\mathbf{p p m})$ \\
\hline Al & 7930 \\
V & 1.700 \\
Th & 0.120 \\
Mn & 3145 \\
\hline
\end{tabular}

Table 4. The heavy elements concentration in sample 3 as obtained from NAA, using the long irradiation facility

\begin{tabular}{cc}
\hline Element & Concentration $(\mathbf{p p m})$ \\
\hline $\mathbf{A g}$ & 11831.7 \\
$\mathbf{S b}$ & 7145.30 \\
$\mathbf{C d}$ & 23.83 \\
$\mathbf{Z n}$ & 6.8200 \\
\hline
\end{tabular}


In addition to lead, aluminum might be also toxic at both environmental and therapeutic levels. Aluminum exposure, apart from causing cholinotoxicity, can induce changes in other neurotransmitter levels since neurotransmitter levels are closely interrelated (Bernardi, 2002). Besides, other adverse developmental effects of aluminum on children and infants were previously reported (Al-Saleh \& Shinwari, 1996).

Cadmium is also considered one of the extremely toxic heavy metals, which can accumulate with time in the body. Due to its low permissible exposure limit, overexposures may occur even in situations where trace quantities of cadmium are found. There are adverse implications due to exposure to environmental $\mathrm{Cd}$, and it has been linked with e.g. an increased risk of dental caries (Amr \& Helal, 2010). Importantly, compounds containing lead and cadmium are also considered potential human carcinogens. However, the mechanism of metal-induced carcinogenesis is still unknown, but one possible pathway may involve the interaction of metals with DNA, either directly or indirectly (Valverde et al., 2001).

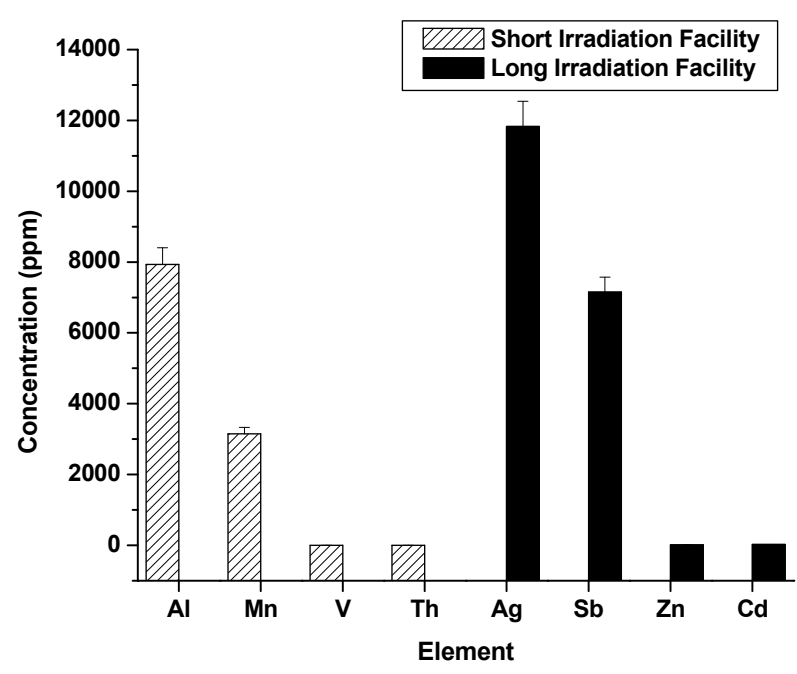

Figure 3. Heavy elements and aluminum concentrations (ppm) in sample 3 as determined by NAA

Besides, Antimony and many of its compounds are toxic, and the effects of antimony poisoning are similar to arsenic poisoning. It has also been found to induce DNA strand lesions but not DNA-protein crosslinks (Mourón et al., 2006). Acute (short-term) exposure to antimony by inhalation in humans results in effects on the skin and eyes. Respiratory effects, such as inflammation of the lungs, chronic bronchitis, and chronic emphysema, are the primary effects noted from chronic (long-term) exposure to antimony in humans via inhalation. Human studies are inconclusive regarding antimony exposure and cancer, while animal studies have reported lung tumors in rats exposed to antimony trioxide via inhalation (Sundar \& Chakravarty, 2010).

On the other hand, silver is intimately associated with environmental contamination of other toxic heavy metals such as mercury and lead. It does not play a known natural biological role in humans, and possible health effects of silver are a disputed subject. Silver itself is not toxic to humans, but most silver salts are. In large doses, silver and compounds containing it can be absorbed into the circulatory system and become deposited in various body tissues, leading to Argyria, which results in a blue-grayish pigmentation of the skin, eyes, and mucous membranes (Hammond, 2000). Interestingly, comparative studies with both silver ions (such as silver acetate) and polyvinylpyrrolidone (PVP)-stabilized silver nanoparticles $(70 \mathrm{~nm}$ ) showed that the effective toxic concentration of silver towards bacteria and human cells is almost the same (Greulich et al., 2012).

Furthermore, vanadium (V) might hold a toxic potential to human health and the environment, especially if the kohl particles are ultra-fine down to nanosize. Due to the high surface-to-volume ratio, small amounts can lead to strong oxidative damage within biological systems, impairing cellular functions as a consequence of their surface reactivity. Recent studies showed that nanoparticulate vanadium oxide has potential vanadium toxicity in human lung cells (Wörle-Knirsch et al., 2007).

Finally, it is worth mentioning here that there is evidence to indicate that, compounds used in cosmetics like 
galena, are likely to form nanocrystals within e.g. hair during blackening (Walter et al., 2006). In our viewpoint, such tiny crystals would much influence the toxicity in living tissues due to their expected higher penetration to cellular and brain barrier membranes. The nanotoxicology of such nanocrystals is an important issue that worth further investigations. In this context, the human health effects resulting from exposure to nanocosmetics should be better explored in order to understand the possible potential hazards of these nanomaterials that already exist in the global market (Bowman \& Van Calster, 2008).

\section{Conclusions}

We have applied an integrated approach by using different atomic and nuclear techniques for probing hazardous elements in some eye-cosmetics, commercially available in Egypt. The applied combined approach allowed for qualitative and quantitative identification of almost the entire elemental content in the studied samples, and helped to overcome the limitation and accuracy of using a single technique. A total of three synthetic and natural eye-liner samples of known origin were analyzed using Energy Dispersive X-ray (EDX), Atomic Absorption Mass Spectroscopy (AA-MS), Elemental Analyzer (EA) and Neutron Activation Analysis (NAA). It was found that lead $(>86 \%)$ represents the main abundant hazardous element in the natural eye-liner sample from African sources. Al and heavy metals like Ag, $\mathrm{Sb}, \mathrm{Mn}, \mathrm{Cd}, \mathrm{Zn}, \mathrm{V}$ and Th were also identified in the later sample using NAA. For the synthetic two samples from French and American sources, the major hazardous element found to be Carbon in high concentration $94 \%$ and 52\% respectively. Producing such eye-cosmetics at the nanoscale would increase their harmful effects due to the ability of toxic nanoparticles to cross the cellular and brain barrier membranes. Whence, the present study highlights the medical and environmental implications of using eye cosmetics with high content of lead and heavy toxic elements. Moreover, the ethical and medical concerns raised in this study emphasize the need for global regulatory rules for the cosmetic industry.

\section{Acknowledgements}

The authors would like to express their thanks and appreciation to Professor Naguib Ashoub, and Dr. Abd El-Ghany El Abd, EAEA, Egypt for their useful comments and discussions.

\section{References}

Ahamed, M., Verma, S., Kumar, A., \& Siddiqui, M. K. J. (2005). Environmental exposure to lead and its correlation with biochemical indices in children. Science of the total environment, 346(1), 48-55. http://dx.doi.org/10.1016/j.scitotenv.2004.12.019.

Al-Ashban, R. M., Aslam, M., \& Shah, A. H. (2004). Kohl (surma): a toxic traditional eye cosmetic study in Saudi Arabia. Public Health, 118(4), 292-298. http://dx.doi.org/10.1016/j.puhe.2003.05.001

Al-Hawi, S. A., Wafai, M. Z., Kalahari, M. R., \& AL-Ugum, W. A. (1980). Light of the Eyes and the Collector of Arts (Vol. 1286, p. 142). King Faisal Center for Research and Islamic Studies, Saudi Arabia.

Al-Hazzaa, S. A., \& Krahn, P. M. (1995). Kohl: a hazardous eyeliner. Inter Ophthal., 19, 83-88. http://dx.doi.org/10.1007/BF00133177

Al-Saleh, I., \& Coat, L. (1995). Lead exposure in Saudi Arabia from the use of traditional cosmetics and medical remedies. Environ. Geochem. Health, 17, 29-31.

Al-Saleh, I., \& Shinwari, N. (1996). Aluminum in Saudi children. Biometals, 9, $385-392$. http://dx.doi.org/10.1007/BF00140608

Amr, M. A., \& Helal, A. I. (2010). Analysis of trace elements in teeth by ICP-MS implication for caries. Journal of physical science, 21(2), 1-12.

Bernardi, R. A. (2002). Protect children from the dangers of lead. HUD announces $\$ 10$ million to help communities. HUD no. 02-022. Washington: US Department of Housing and Urban Development.

Bowman, D. M., \& Van Calster, G. (2008). Flawless or Fallible? A Review of the Applicability of the European Union's Cosmetics Directive in Relation to Nano-Cosmetics. Studies in Ethics, Law, and Technology, 2(3).

Erdtmann, G., \& Petri, H. (1986). Nuclear activation analysis: fundamentals and techniques. In P. J. Elving (Ed.), Treatise of Analytical Chemistry (2nd Ed., p. 414). New York: Wiley.

Greulich, C., Braun, D., Peetsch, A., Diendorf, J., Siebers, B., Epple, M., \& Köller, M. (2012). The toxic effect of silver ions and silver nanoparticles towards bacteria and human cells occurs in the same concentration range. RSC Advances, 2(17), 6981-6987. http://dx.doi.org/10.1039/c2ra20684f

Hammond, C. R. (2000). The Elements, in Handbook of Chemistry and Physics $81^{\text {st }}$ edition. CRC press. ISBN 0-8493-0481-4. 
Hardy, A. D., Walton, R. I., \& Vaishnave, R. (2004). Composition of eye cosmetics (kohls) used in Cairo. J. Enviiron. Health Res., 14(1), 83-91. http://dx.doi.org/10.1080/09603120310001633859

Hassan, A. M., El-Enany, N., El-Tanahy, Z., \& Abdel-Momen, M. A. (1994). Multielement measurements of various industrial samples by neutron capture prompt gamma-ray activation analysis. Nucl. Geophys., 8(1), 91-98.

Karim, N. J., \& Hartmut, G. H. (2005). Characterization of a hazardous eyeliner (kohl) by confocal Raman microscopy. Jounal of Hazardous Materials, B124, 236-240.

Karri, S., Saper, R., \& Kales, S. (2008). Lead Encephalopathy Due to Traditional Medicines. Curr Drug Saf., 3(1), 54-59. http://dx.doi.org/10.2174/157488608783333907

Khassouni, S. (1993). Utilisation du khol: risqué d'intoxication (3rd Ed., p. 188).

Klaasen, C. D. (1996). Casarett and Doull's Toxicology, the Basic Science of Poisons (5th ed.). New York: McGraw-Hill Book Company.

Landsberger, S. J. (1992). Analytical methodologies for instrumental neutron activation analysis of airborne particulate matter. J. Trace Microprobe Tech., 10, 1.

Lederer, C. M., \& Shirley, V. S. (1997). Table of isotopes (8th ed.). New York: Wiley.

Lekouch, N., Sedki, A., Nejmeddine, A., \& Gamon, S. (2001). Lead and traditional Moroccan pharmacopoein. The Science of the Total Environment, 280, 39-34. http://dx.doi.org/10.1016/S0048-9697(01)00801-4

Martinez, T., Lartigue, J., Navarrete, M., Avila, P., Lopez, C., Cabrera, L., \& Vilchis, V. (1997). Determination of pollutants in dwellings by neutron activation analysis and X-ray fluorescence. J. Radioanal. Nucl. Chem., 216, 37-39. http://dx.doi.org/10.1007/BF02034492

Mourón, S., Grillo, C., Dulout, F., \& Golijow, C. (2006). Induction of DNA strand breaks, DNA-protein crosslinks and sister chromatid exchanges by arsenite in a human lung cell line. Toxicology in Vitro, 20(3), 279-285. http://dx.doi.org/10.1016/j.tiv.2005.07.005.

Nada, A., El-Bahi, S. M., Abdel-Ghany, H. A., \& Hassan, A. M. (2001). Elemental investigation of some Egyptian vehicle motor alloys. Applied Radiation and Isotopes, 55, 575-580. http://dx.doi.org/10.1016/S0969-8043(01)00099-9

Needleman, H. L., Schell, A., Bellinger, D., \& Alfred, E. N. (1990). The long-term effects of exposure to low doses of lead in childhood. An eleven-year follow-up report. N. Engl. J. Med., $332,83$. http://dx.doi.org/10.1056/NEJM199001113220203

Nir, A., Tamir, A., Zelmuk, A., \& Iancu, T. C. (1992). Is eye cosmetic a source of lead poisoning. Isr. J. Med. Sci., $28(7), 417$.

Parry, C., \& Eaton, J. (1991). Kohl: a lead-hazardous eye makeup from the Third World to the First World. Environmental Health Perspectives, 94, 121. http://dx.doi.org/10.2307/3431304.

Schwartz, J., \& Otto, D. (1991). Lead and minor hearing impairment. Archives of Environmental Health: An International Journal, 46(5), 300-305. http://dx.doi.org/10.1080/00039896.1991.9934391

Sundar, S., \& Chakravarty, J. (2010). Antimony toxicity. International journal of environmental research and public health, 7(12), 4267-4277. http://dx.doi.org/10.3390/ijerph7124267

Tong, S., von Schirnding, Y. E., \& Prapamontol, T. (2000). Environmental lead exposure: a public problem of global dimension. Bulletin of the World Health Organization, 78, 1068-1077. http://dx.doi.org/10.1590/S0042-96862000000900003

Valverde, M., Trejo, C., \& Rojas, E. (2001). Is the capacity of lead acetate and cadmium chloride to induce genotoxic damage due to direct DNA-metal interaction? Mutagenesis, 16(3), 265-270. http://dx.doi.org/10.1093/mutage/16.3.265

Walter, P., Martinetto, P., Tsoucaris, G., Brniaux, R., Lefebvre, M. A., Richard, G., ... Dooryhee, E. (1999). Making make-up in Ancient Egypt. Nature, 397(6719), 483-484. http://dx.doi.org/10.1038/17240

Walter, P., Welcomme, E., Hallégot, P., Zaluzec, N. J., Deeb, C., Castaing, J., ... Tsoucaris, G. (2006). Early use of $\mathrm{PbS}$ nanotechnology for an ancient hair dyeing formula. Nano letters, 6(10), 2215-2219. http://dx.doi.org/10.1021/n1061493u

Willard, H. H., Merritt Jr, L. L., Dean, J. A., \& Settle Jr, F. A. (1988). Instrumental methods of analysis. USA: 
Wadsworth.

Wörle-Knirsch, J. M., Kern, K., Schleh, C., Adelhelm, C., Feldmann, C., \& Krug, H. F. (2007). Nanoparticulate vanadium oxide potentiated vanadium toxicity in human lung cells. Environmental science \& technology, 41(1), 331-336. http://dx.doi.org/10.1021/es061140x

Yoshida, T., Yoshioka, Y., \& Tsutsumi, Y. (2011). [The safety assessment of nanomaterials for development of nano-cosmetics]. Yakugaku zasshi: Journal of the Pharmaceutical Society of Japan, 132(11), 1231-1236. http://dx.doi.org/10.1248/yakushi.12-00232-4

\section{Copyrights}

Copyright for this article is retained by the author(s), with first publication rights granted to the journal.

This is an open-access article distributed under the terms and conditions of the Creative Commons Attribution license (http://creativecommons.org/licenses/by/3.0/). 